\title{
Nutritional support in liver disease
}

\author{
D B A Silk, S J D O'Keefe, C Wicks
}

It has been recognised for many years that patients with chronic parenchymal liver disease are malnourished. Dr Roger Williams and his colleagues at King's were one of the first to formally document nutritional status in their patients when O'Keefe et $a l^{1}$ reported that significant numbers of their patients had clinical, biochemical, haematological and immunological variables thought to be indicative of protein calorie malnutrition. Furthermore their data showed links between malnutrition, anergy, sepsis, and mortality, suggesting that efforts to improve nutritional status might improve prognosis by reducing the known high incidence of infective complications. Subsequently other workers have confirmed these findings. ${ }^{2}$ At Central Middlesex Hospital, Keohane et al found a marked similarity between the nutritional status of patients admitted for management of complications of cirrhosis and those patients without liver disease who in the opinion of the nutritional support team required nutritional support. ${ }^{4}$

Impaired dietary intake is almost certainly one of the principal causes for nutritional deficiencies in patients with chronic liver disease. ${ }^{2-6}$ Documented mean protein and caloric intake was as low as $47 \mathrm{~g} / \mathrm{d}$ and $1320 \mathrm{kcal} / \mathrm{d}^{23}$ respectively. Reduced nutrient intake may arise as a result of associated anorexia and nausea and also because dietary protein intake is often restricted for therapeutic reasons as part of the management of hepatic encephalopathy. ${ }^{5}$

Evidence is accumulating which suggests that nutritional deficiencies also arise because of impaired digestion and absorption of nutrients. Exocrine pancreatic insufficiency has been shown in patients with cirrhosis ${ }^{7}$ as well as malabsorption of D-xylose, thiamine, folic acid, and fat. ${ }^{8}$ Because of the central role of the liver in nutrient metabolism, requirement levels for most nutrients change in liver failure and in some instances, non-essential nutrients that are normally synthesised or activated by the liver can become essential, such as choline and vitamin D. ${ }^{9}$ As the liver also acts as a store for many vitamins, increased urinary losses contribute to deficiencies.

By virtue of its oxidative and synthetic functions, the liver plays a regulatory role in amino acid homeostasis. Before his arrival at King's, O'Keefe and his colleagues showed by isotopic tracer techniques that the 'catabolic' loss of body nitrogen after elective surgery was more a consequence of reduced protein synthesis, secondary to inadequate dietary intake, than the classical view of accelerated protein catabolism that was derived from nitrogen balance studies. ${ }^{10}$ Similar methodology was then applied to the study of protein turnover in patients with cirrhosis and fulminant hepatic failure. Tyrosine, an aromatic amino acid, and whole body protein turnover was measured by a constant eight hour intravenous infusion of ${ }^{14} \mathrm{C}$ labelled tyrosine tracer. ${ }^{11}$ In the fasting state, the increase in aromatic amino acid accumulation in blood was shown to be directly related to increased endogenous protein breakdown. Calculations showed that the input of amino acids into the plasma from endogenous protein breakdown was five times higher in cirrhosis, and 12 times higher in patients with fulminant hepatic failure, than the normal input from dietary protein. Consequently, efforts to suppress protein catabolism would be more effective than dietary restriction in preventing the possible toxic accumulation of aromatic amino acids in the blood stream. Furthermore, direct measurements of aromatic amino acid oxidation showed that although hepatic oxidative clearance was reduced, it continued even in fulminant hepatic failure such that a dietary intake of at least $60 \mathrm{~g}$ protein would be required to maintain body protein equilibrium. In similar studies, Swart and colleagues used a single oral dose of ${ }^{15} \mathrm{~N}$ labelled glycine to measure nitrogen kinetics in stable cirrhotic patients in the fed and fasting state.$^{12}$ Contrary to their hypothesis and expectation, dietary protein appeared to be more efficiently handled in cirrhotic patients than in controls, being associated with increased protein synthesis rates and not the expected increase in amino acid oxidation rates. This led them to further hypothesise that patients with cirrhosis have higher protein requirements because of an accelerated rate of transition from the fed to fasting state because of diminished liver glycogen stores. Thus more rapid transition to glyconeogenesis from amino acids would fill the energy gap resulting from low glycogen stores. They have subsequently presented evidence supporting this concept showing that the provision of a late evening meal improved the efficiency of nitrogen metabolism in cirrhotic patients. ${ }^{13}$ It should be noted, however, that these studies were uncontrolled and it is likely that the same benefits will be seen in normal non-cirrhotic individuals. Furthermore it should be noted that no kinetic study to date, including those of O'Keefe and Swart described above and those of Millikan ${ }^{14}$ and Mullen, ${ }^{15}$ has clearly shown increased oxidative losses of protein in patients with liver disease. Consequently, the high incidence of protein deficiency seen in patients with liver disease is almost certainly a consequence of a decreased dietary intake resulting from the anorexia of chronic illness. These observations therefore support the conclusion that (a) efforts should be made to maintain normal dietary intakes in patients with stable chronic liver disease and, (b) patients with more severe liver dysfunction will require dietary modification and nutritional supplementation. 
Nutritional support in the presence of hepatic encephalopathy: the dilemma

It is a feature of the natural history of the disease that many patients with cirrhosis develop hepatic encephalopathy and coma at some stage during the course of their illness. As defective hepatic metabolism of protein, with the accumulation of nitrogenous compounds in the bloodstream, has been implicated in the aetiology of encephalopathy, it has been customary to restrict dietary protein intake even in malnourished patients. This might well exacerbate the problem in the long term, however, as protein deficiency leads to infections ${ }^{16}$ and infection is one of the most common precipitating causes of encephalopathy. ${ }^{17}$

During the last 15 years much research has been directed towards examining the role of altered amino acid metabolism in the pathogenesis of hepatic encephalopathy, in particular the relation between imbalances of plasma amino acid profiles and brain false neurotransmitter synthesis. New approaches to the management of malnutrition and the treatment of encephalopathy in patients with cirrhosis has emerged based on the use of branched chain enriched amino acid formulations.

\section{NUTRITIONAL SUPPORT STRATEGIES}

The literature pertaining to nutritional support of patients with liver disease is not easy to comprehend, because of the heterogeneity of the patient groups studied, differences in the aims and goals of the studies, differences in nutritional regimens prescribed and disagreements about end point objectives. The ensuing text will attempt to categorise results of work concerned with the nutritional support of patients with liver disease who are predominantly non-encephalopathic, those with alcoholic hepatitis, those with cirrhosis with evidence of coexisting hepatic encephalopathy, those patients with fulminant hepatic failure, and in those with end stage liver disease coming to human orthotopic liver transplantation.

\section{NUTRITIONAL SUPPORT IN THE ABSENCE OF HEPATIC ENCEPHALOPATHY}

When there is no impairment of mental function the nutritional state of malnourished patients with parenchymal liver disease can be improved by standard means. The current philosophy of the Liver Unit at King's College Hospital is to achieve an increased nutritional intake whenever possible by either encouraging the patients to eat more normal food with or without the use of oral supplements or by instituting enteral nutrition using standard polymeric enteral diets. The adoption of such a philosophy is supported by the results of two recent controlled clinical trials, one of which shows that nutritional intake in hospitalised patients with alcoholic liver disease can be increased by means of oral supplements. ${ }^{2}$ In the other the clinical state and inpatient hospital mortality of enterally fed cirrhotic patients were both significantly better compared with those in controls who were fed the normal ward diet. ${ }^{3}$

\section{ALCOHOLIC HEPATITIS}

As emphasised by the King's group ${ }^{6}$ acute alcoholic hepatitis is a potentially reversible condition, but one with an overall inpatient mortality of up to $60 \%$. As shown by the King's group ${ }^{2}$ and by others ${ }^{18}$ the majority of these patients are at least moderately if not severely malnourished creating the rationale for nutritional therapy in this condition. The results have been critically reviewed by Achord. ${ }^{18}$ The trial by the King's group $^{6}$ and three others ${ }^{19-21}$ are worthy of mention. In the first Nasrallah and Galambos ${ }^{19}$ showed that 28 days of peripheral amino acid infusion resulted in significant improvements of serum albumin, bilirubin, and mortality in the treatment group as compared with the control group. In the Veterans Administration cooperative study ${ }^{20}$ those patients randomised to receive supplemental enteral alimentation containing branched chain amino acids showed an improvement in objective assessment of nutritional status, but not mortality as compared with those patients randomised to an ad libitum hospital diet. In a further study 73 patients with alcoholic hepatitis whose oral diet was supplemented with central venous alimentation showed no improvement in nutritional status nor mortality. ${ }^{21}$ The results of the King's study involving 64 patients $^{6}$ who were randomised to receive a control diet alone, or with added enteral or intravenous supplements, no differences were noted in nitrogen balance, nutritional status or mortality. Like others, the King's group are not discouraged by their results, they continue to appreciate the importance of nutritional support as a means of preventing deterioration in nutritional status in alcoholic hepatitis while other forms of therapy can be implemented. Moreover they recognise the imperfection of study design, thus in order to detect a $25 \%$ difference within $95 \%$ confidence limits an estimated 45 patients in each group will be required. ${ }^{18} \mathrm{~A}$ number not contained in their ${ }^{6}$ or the other ${ }^{19-21}$ prospectively randomised studies.

\section{NUTRITIONAL SUPPORT IN THE PRESENCE OF} HEPATIC ENCEPHALOPATHY

One of the continuing interests of the King's group are the biochemical mechanisms involved in the pathogenesis of hepatic encephalopathy, which they have reviewed ${ }^{1822}$ on more than one occasion. Of particular relevance to the nutritional support of encephalopathic patients has been the demonstration of increases in plasma concentrations of the aromatic amino acids, phenylalanine and tyrosine, as well as methionine and tryptophan, these changes have been mirrored by reductions in plasma concentrations of the branched chain amino acids valine, leucine and isoleucine. Much discussion has taken place as to the cause of these changes, ${ }^{522}$ to which the King's group have made major contributions. As discussed earlier O'Keefe and colleagues" showed that the increased aromatic amino acid concentrations in blood were more related to increased endogenous protein breakdown than dietary intake, plus reduced hepatic oxidative clearance. The explanation for reduced branched chain amino acid concentrations is less 
clear. Initial studies of Munro and colleagues suggested that the increased insulin concentrations that resulted from defective hepatic clearance, promoted the uptake of branched chain amino acids into peripheral tissues. ${ }^{23}$ Subsequent studies by Marchesini and colleagues, however, using a euglycemic insulin infusion, failed to uphold this view. ${ }^{24} \mathrm{~A}$ more likely explanation is that the branched chain amino acids form a useful alternative energy source in patients with defective hepatic metabolism.

The relationship of the disturbed plasma amino acid profiles to the pathogenesis of hepatic encephalopathy and the development of the false neurotransmitter hypothesis has been reviewed in detail by the King's group ${ }^{5225-27}$ and the rationale underlying the use of branched chain amino acid therapy in patients with hepatic encephalopathy originally proposed by Fischer et $a l^{23}{ }^{30}$ has been fully documented. ${ }^{52}$ Fischer and his colleagues were the first to create a specially formulated amino acid solution for intravenous use that contained considerably decreased amounts of phenylalanine, tyrosine, tryptophan, threonine, and glycine and increased amounts of the branched chain amino acids, leucine, isoleucine and valine, as well as arginine. After showing that survival in encephalopathic dogs receiving the formulation was appreciably increased compared with dogs receiving a standard intravenous formulation of amino acids ${ }^{25}$ clinical studies were commenced. The results were encouraging for not only did the infusion of the amino acid mixture correct the plasma amino acid profiles of patients, but their neuropsychiatric state seemed to improve. ${ }^{28}$ In passing they found that positive nitrogen balance was achieved. The innovative studies of Fischer and colleagues have stimulated much further clinical research into the use of amino acid mixtures enriched with branched chain amino acids and deficient in aromatic amino acids. Horst $e t a l^{31}$ pointed out how difficult it is to draw conclusions from the data, particularly those derived from uncontrolled trials. The controlled trials that have been performed have, however, evaluated different amino acid mixtures administered in different ways using different end points in patients with different types and degrees of encephalopathy. Moreover, there seems little doubt that Fischer's original concept was concerned with the use of these specially formulated amino acid solutions as primary therapy for the hepatic encephalopathy. As appreciated by the King's group, the emphasis of this approach has shifted from primary treatment of the encephalopathy to safe provision of nutritional support, which at the same time does not have the expected deleterious effect on the patients neuropsychiatric state, as expressed in a recent review. ${ }^{32}$ Furthermore, from a theoretical point of view, protein synthesis will be more efficient if the composition of the precursor amino acid pool is balanced rather than containing an excess of aromatic and a depletion of branched chain amino acids. ${ }^{33}$

Silk has recently undertaken a critical analysis of the therapeutic efficacies of branched chain amino acids in cirrhotic patients with hepatic encephalopathy ${ }^{29}$ and has emphasised the need to consider separate therapy in those with latent, chronic, and acute forms of encephalopathy.

Latent (sub-clinical) portal systemic encephalopathy Egberts et $\mathrm{l}^{32}$ are the only group to have restricted their study to patients who have never been clinically encephalopathic and who have never received dietary restriction as part of their clinical management. Taking into account the crossover design, appreciable improvements attributable to branched chain amino acid treatment could be shown in psychomotor function, attention, and practical intelligence. The study lasted only a week, however, so the benefits should be considered at best to be very short term.

\section{CHRONIC PORTAL SYSTEMIC ENCEPHALOPATHY}

Three groups have addressed the question of whether branched chain amino acids supplementation has a beneficial effect on the mental state on patients with cirrhosis and chronic portal systemic encephalopathy. ${ }^{31}{ }^{35}{ }^{36}$ In neither of the two small and short term crossover trials $^{3536}$ was there a question that branched chain amino acids supplementation had any appreciable effect on the mental state of patients studied. In the longer term and larger trial of Horst et $a l^{31}$ the branched chain amino acid supplemented diet, Hepaticaid seemed to have a distinct advantage. This diet was as effective in inducing positive nitrogen balance as was an equivalent amount of protein, and encephalopathy at the same time was induced far less often during the four weeks of trial. As outlined previously, if these observations are confirmed then the potential role of branched chain acids in chronic portal systemic encephalopathy will have shifted from that of a primary therapeutic agent of encephalopathy to a means of more safety improving the nutritional state of these patients.

\section{ACUTE PORTAL SYSTEMIC ENCEPHALOPATHY}

Three simple randomised controlled clinical trials have addressed themselves to the efficacy of branched chain amino acids administered parenterally to patients with acute portal systemic encephalopathy. ${ }^{37-39}$ In two of the trials $^{3738}$ no significant benefit of branched chain amino acids was seen in respect of either encephalopathy or mortality. In the trial of Cerra et $a l^{39}$ promising results were obtained. A significant beneficial effect of parenterally administered branched chain amino acid mixture on encephalopathy and mortality was obtained. Only one study has compared the effect of branched chain enriched formulations to standard formulations, however, and it is important to note that in this study survival was actually longer in those given a standard formulation. ${ }^{+0}$ Thus, although for theoretical reasons it would seem better to use a specialised amino acid formula, cost effectiveness still needs to be proved, particularly as O'Keefe and colleagues failed to show any exacerbation of hepatic encephalopathy in patients given standard amino 
acid infusions. ${ }^{41}$ There is thus a clear need for further controlled studies in this group.

\section{FULMINANT HEPATIC FAILURE}

The King's Unit continues to have a major interest in the management of patients with fulminant hepatic failure and in recent years have addressed themselves to the effect of the illness per se and the various therapeutic manoeuvres on the nutritional status of these patients. In the past, emphasis has been on maintaining protein free intravenous glucose infusions in order to prevent neuroglycopenia and reduce ammonia production, but studies at King's have shown that despite massive hepatic necrosis, amino acid oxidative losses continue ${ }^{11}$ and may be exacerbated by artificial liver support systems, ${ }^{42}$ suggesting a continuing need for amino acids. As amino acids are required for hepatic regeneration, substrate supply must be maintained. Isotope incorporation studies also showed that, in contrast with the situation in patients with chronic liver disease, the low albumin concentrations seen in patients with fulminant hepatic failure were a consequence of decreased albumin synthesis. Furthermore, infusions of ${ }^{14} \mathrm{C}$ labelled phenylalanine showed an association between reduced phenylalanine oxidation, reduced incorporation into albumin and mortality, such that no individual with an oxidation rate below $0.05 \mathrm{mmol} / \mathrm{h}$ and a reduced incorporation into albumin below $0.3 \% / \mathrm{d}$ survived. ${ }^{43}$ It is very doubtful that nutritional support, in contrast with metabolic support, would have any role in these individuals and the only hope would be timely liver transplantation. On the other hand, complete recovery was seen in some of the patients with less suppressed rates suggesting that close attention to nutritional support might form a decisive factor in their outcome.

Most recently the King's group have estimated the nitrogen requirements of these patients and as a prelude to establishing a nutritional support programme have shown that in contrast with previous opinions, patients with liver failure tolerate lipid emulsions well. ${ }^{44}$

\section{ORTHOTOPIC LIVER TRANSPLANTATION}

As outlined earlier in this supplement the King's group have made very great strides in the area of orthotopic liver transplantation. They were the first to document that successful liver transplantation is associated with a severe state of protein catabolism indicating the need for early postoperative feeding. ${ }^{45}$ The Boston group have subsequently measured aromatic and branched chain amino acid metabolic rates before and after liver transplantation and have shown that liver transplantation rapidly normalises aromatic amino acid clearance and that branched chain oxidation increases above normal. ${ }^{46}$ Thus, there appears to be a little need for specialised amino acid formulations after successful liver transplantation, but the overall requirement for dietary protein is high. Few studies have addressed the question of energy requirements but preliminary investigations from the Mayo
Clinic, based on indirect calorimetry, have failed to show increased energy expenditure during the first week after liver transplantation. ${ }^{47}$ The King's Unit are currently turning their attention to assessing nutritional status in their patients with end stage liver disease undergoing transplantation. This has been an important step to take. Recent studies do highlight how malnutrition is present preoperatively in these patients. ${ }^{48}$ Aggressive nutritional support will probably benefit outcome, and preliminary data certainly from America already indicate how the length of stay in the Intensive Care Unit can be shortened by instituting early postoperative nutrition. ${ }^{49}$

1 O'Keefe SJD, El-Zayadi A, Carraher T, Davies M, Williams R. Malnutrition and immuno-competence in patients with liver disease. Lancet 1980; ii: 615-7.

2 Bunout D, Aicardi V, Hirsch S, et al. Nutritional support in hospitalised patients with alcoholic liver disease. Eur $\mathcal{F}$ Clin Nutr 1989; 43: 615-21.

3 Cabre E, Gonzalez-Huiz F, Abad-Lacruz A, et al. Effect of total enteral nutrition on the short term outcome of severely total enteral nutrition on the short term outcome of severely

4 Keohane PP, Attrill H, Grimble G, Spiller R, Frost P, Silk DBA. Enteral nutrition in malnourished patients with hepatic cirrhosis and acute encephalopathy. $\mathcal{F}$ Parent Ent Nutr 1983; 7: 346-50.

5 Silk DBA. Nutrition. In: Jewell PB, Mahida YR, eds. Topics and gastroenterology 15. Oxford: Blackwell Scientific Publications, 1987: 41-56.

6 Calvey H, Davies M, Williams R. Controlled trial of nutritional supplementation, with and without branched chain amino acid enrichment in treatment with acute alcoholic hepatitis. F Hepatol 1985; 1: 141-51.

7 Van Goidsenhoven GE, Henke WJ, Vacca JB, Knight WA. Pancreatic function in cirrhosis of the liver. Am $\mathcal{F}$ Dig Dis $1963 ; 8: 160-73$.

8 Mezey G. Intestinal function in chronic alcoholism. Ann NY Acad Sci 1975; 252: 215-27.

9 Chowla RK, Wolf DC, Kutner MH, Bonkovsky HL. Choline may be an essential nutrient in malnourished patients with cirrhosis. Gastroenterology 1989; 97: 1514-20.

10 O'Keefe SJD, Sender PM, James WPT. 'Catabolic' loss of body nitrogen in response to surgery. Lancet 1974; 00: 1034-7.

11 O'Keefe SJD, Abraham R, Zayadi A, Marshall W, Davies M, Williams R. Increased plasma tyrosine concentrations in patients with cirrhosis and fulminant hepatic failure associated with increased plasma tyrosine flux and reduced hepatic oxidation a capacity. Gastroenterology 1981; 81: 1017-24.

12 Swart GR, Van den Berg JWO, Wattimena JLD, Rietveld T, Van Vuure JK, Fraenkel M. Elevated protein requirements in cirrhosis of the liver, investigated by whole body protein turnover studies. Clin Sci 1988; 75: 101-7.

13 Swart GR, Zillikens MC, van Vuure JK, van den Berg TWO Effect of a late evening meal on nitrogen balance in patient with cirrhosis of the liver. Br Med F 1989; 299: 1202-3.

14 Millikan WJ, Henderson JM, Galloway JR, et al. In vivo measurement of leucine metabolism with stable isotopes in normal subjects and in those with cirrhosis fed conventional and branch amino acid enriched diets. Surgery 1985; 98: 405-12.

15 Mullen KD, Denne SC, McCullough AJ, et al. Leucine metabolism in stable cirrhosis. Hepatology 0000; 6: 622-30.

16 Scrimshaw NS. Protein deficiency and infective disease. In: Munroe HN, Allisson JB, eds. Mamalian protein metabolism. Munroe HN, Allisson JB, eds. Mamalian protein metabolism. chap 23

17 Lanthier PL, Morgan MY. Lactitol in the treatment of chronic hepatic encephalopathy: on open comparison with lactulose. Gut 1985; 26: 415-20.

18 Achord JL. Malnutrition and the role of nutritional support in alcoholic liver disease. Am F Gastroenterol 1987; 82: 1-7.

19 Nasrallah SM, Galambos JT. Amino acid therapy of alcoholic hepatitis. Lancet 1980; ii: 1276-8.

20 Mendenhall C, Bongiovanni G, Goldberg S, et al. VA co-operative study on alcoholic hepatitis. III: Changes in protein calorie malnutrition associated with 30 days of protein calorie malnutrition associated with 30 days of hospitalization with and without

21 Naveau S, Pelletier G, Poynard T. A randomized clinical trial of supplementary parenteral nutrition in jaundiced alcoholic of supplementary parenteral nutrition in jaund

22 Crossley IR, Wardall EN, Williams R. Biochemical mechanisms of hepatic encephalopathy. Clin Sci 1983; 64: 247-52.

23 Munro HN, Fernstrom JD, Wurtman RJ. Insulin, plasma amino acid imbalance and hepatic comas. Lancet 1975; 00: 986.

24 Marchesini G, Forlani G, Zollizetto-Eli M, et al. Effect of euglycemic insulin infusion on plasma levels of branch chain amino acids in cirrhosis. Hepatology 1983; 32: 184-7.

25 James JH, Ziparo V, Jeppsson B, Fischer JE. Hyperaminoaemia, plasma amino acid inbalance, and blood brain amino 
acid transport: a unified theory of portal/systemic encephalopathy. Lancet ii: $772-5$.

26 McCullough AJ, Mullen KD, Tavill AS. Branched chain amino acids as nutritional therapy in liver disease: death or surfeit. Hepatology 1983; 3: 269-71.

27 Fischer JE. Amino acids in hepatic coma. Dig Dis Sci 1982; 27: 97-102.

28 Fischer JE, Rosen HM, Ebeid AM, James JH, Keane JM, Soeters PB. The effect of normalisation of plasma amino acids

29 Silk DBA. Branched chain amino acids in liver disease: fact or fantasy? Gut 1986; 27: 103-10.

30 Fischer JE, Funovics JM, Aguirre A, et al. The role of plasma amino acids in hepatic encephalopathy. Surgery 1975; 70: 276-90.

31 Horst D, Grace ND, Conn HO, et al. Comparison of dietary protein with an oral, branched chain-enriched amino acid supplement in chronic portal systemic encephalopathy. A rapplement in chronic portal systemic encephalopathy.

32 Blackburn GL, O'Keefe SJD. Editorial. Nutrition in liver failure. Gastroenterology 1989; 97(4): 1049-51.

33 O'Keefe SJD, Ogden J, Dicker J. Enteral and parenteral branched chain amino acid-supplemented nutritional support in patients with encephalopathy due to alcoholic liver disease. F Parent Ent Nutr 1987; 11(5): 447-53.

34 Egbergts $E H$, Schomerus $H$, Hamster $W$, Jurgens $P$. Branched chain amino acids in the treatment of latent portal systemic encephalopathy. A double-blind placeboportal systemic encephalopathy. A double-blind placebo-
controlled crossover study. Gastroenterology 1985; 88: controlled

35 Eriksson LS, Person A, Wahren J. Branched chain amino acids in the treatment of chronic hepatic encephalopathy. Gut 1983; 23: 801-93.

36 McGhee A, Henderson JM, Millikan WJ, et al. Comparison of the effects of hepatic aid and a case in modular diet on encephalopathy, plasma amino acids and nitrogen balance in encephalopathy, plasma amino acids and nitrogen
cirrhotic patients. Ann Surg 1983; 197: 288-93.

37 Rossi-Fanelli F, Riggio O, Cangiano C, et al. Branched chain amino acids vs latulose in the treatment of hepatic coma: a controlled study. Dig Dis Sci 1982; 27: 929-35.

38 Wahren J, Denis J, Desurmont $\mathrm{P}$, et al. Is intravenous administration of branched chain amino acids effective in the treatment of hepatic encephalopathy? A multicenter study. Hepatology 1983; 3: 475-80.

39 Cerra FB, Cheung NK, Fischer JE, et al. Disease-specific amino acid infusion (FO80) in hepatic encephalopathy: A prospective randomized, double blind controlled trial. 7 Parent Ent Nutr 1985; 9: 288-95

40 Michel H, Pomier-Layrargues G, Aubin JP, et al. Treatment of hepatic encephalopathy by infusion of a modified amino acid solution: results of a controlled study in 47 cirrhotic patients. In: Capocaccia L, Fischer JE, Rossi-Fanelli F, eds. Hepatic encephalopathy in chronic liver failure. New York: Plenum, 1984: 301-10.

41 O'Keefe SJD, Ogden J, Ramjee G, Moldawer LL. Short-term effects of an intravenous infusion of a nutrient solution containing amino acids, glucose and insulin on leucine turnover and amino acid metabolism in patients with liver failure. $\mathcal{F}$ Hepatol $1988 ; 6(1): 101-8$.

42 Chase RA, Davies M, Trewby PN, Silk DBA, Williams R. Plasma amino acid levels in patients with fulminant hepatic failure treated with polyacrylonitrile haemodialysis. Gastroenterology 1978; 75: $1033-40$.

43 O'Keefe SJD, Ogden J, Rund J. The use of ${ }^{14} \mathrm{C}$ labelled phenylalanine to trace deranged aromatic amino acid metaphenylalanine to trace deranged aromatic amino acid metanostic potential. Gastroenterology 1989; 96(5): A641.

44 Forbes $A$, Wicks $C$. Fulminant hepatic failure nutrition and fat clearance. Recent Advances in Nutrition 1990; 1: 67-9A

45 O'Keefe SJD, Abraham RR, Davis M, Williams R. Protein turnover in acute and chronic liver disease. Acta Clin Scand 1981; suppl 507: 91-101.

46 Shanbhogue RLK, Bristrian BR, Lakshman K, et al. Whole body leucine phenylalanine and tyrosine kinetics in end stage liver disease before and after hepatic liver transplantation. Metabolism 1987; 36(11): 1047-53.

47 Di Cecco SR, Plevak DJ, Wiesner RH, O'Keefe SJD, et al. Do we accurately estimate caloric and nitrogen requirements in we accurately estimate caloric and nitrogen requirements
the liver transplant patient? Hepatology 1990; 12(4): 978 .

48 Di Cecco SR, Wieners EJ, Wiesner RH, Southorn PA, Plevak DJ, Krom RAF. Assessment of nutritional status of patients with $\mathrm{N}$-stage liver disease undergoing liver transplantation. Mayo Clin Proc 1989; 64: 95-102.

49 Reilly J, Mehta R, Teperman L et al. Nutritional support after liver transplantation: a randomised prospective study. $\mathcal{F}$ Parent Ent Nutr 1990; 14: 386-91. 